\title{
Modeling and Analysis of a Multilevel Parallel Hybrid Active Power Filter
}

\author{
Tugce Demirdelen \\ Department of Electrical and \\ Electronics Engineering, Cukurova \\ University, Turkey \\ tdemirdelen@cu.edu.tr
}

\author{
R. Ilker Kayaalp \\ Department of Electrical and \\ Electronics Engineering, Cukurova \\ University, Turkey \\ ikayalap@cu.edu.tr
}

\author{
Mehmet Tumay \\ Department of Electrical and \\ Electronics Engineering, Cukurova \\ University, Turkey \\ mtumay@cu.edu.tr
}

\begin{abstract}
This paper introduces a new control approach for the Multilevel Parallel Hybrid Active Power Filter (M-PHAPF) which can compensate harmonics and variable reactive power demand of loads by controlling the DC link voltage adaptively in medium voltage applications. By the means of this novel control method, M-PHAPF obtains a better and more efficient performance in the compensation of harmonics and reactive power compared to when using conventional control methods. The performance and stability of the proposed method are verified with a simulation model realized in PSCAD/EMTDC with different case studies. The simulation results demonstrate that harmonic compensation performance meets the requirements of the IEEE-519 standard.
\end{abstract}

Keywords- Harmonics; Parallel Hybrid Active Filter; reactive power compensation; simulation; PSCAD/EMTDC.

\section{INTRODUCTION}

In power transmission/distribution systems, the intensive use of nonlinear loads causes several power quality problems. The grid voltage and currents become non sinusoidal and harmonic distortion appears. The use of passive filters is one of the traditional solutions to reduce current harmonics. However, it provides a low filtering performance and its filtering performance depends on the changing conditions of power systems.

With the remarkable development of semiconductor switching devices, active power filters (APF) have gain interest and have been put into practical use as they have the ability to overcome the disadvantages of passive filters. APF are more effective in harmonic compensation and provide superior filtering performance [1-7]. Although APF are an accomplished compensation system, the cost of APF significantly increases with increasing power ratings. To overcome this contradiction, passive and active filters are used together as a single device called a Hybrid Active Power Filter (HAPF). In the literature, different HAPF topologies which are the combination of the series and/or parallel APF and passive filters are proposed [7-21]. The main purpose of the development of HAPF topologies is to provide the compensation requirements of dominant harmonics and reactive power demand of nonlinear loads with passive filters and decrease the ratings and also costs of APF. PHAPF which is formed from series connection of passive filter and APF come forward in HAPF topologies. The most significant advantage of the PHAPF topology is that the passive filter capacitor holds the major part of fundamental voltage across its terminals and APF part holds only the required voltage for harmonic compensation on the DC link with the help of series connection of passive filters and inverters. This advantage provides reduction in power ratings and switching losses of APF.

The controller design of PHAPF is a significant and challenging task due to its impact on the performance and stability of the overall system. For this reason, different reference generation and control methods such as pq theory $[12,19,21]$, fast fourier transform [19], dq theory [22-27], fuzzy controller $[14,16]$, proportional resonant current controller [17] etc. have been applied to PHAPF. The current controller, responsible for producing reference currents, is an important part of the PHAPF controller. According to the current control strategy, direct and indirect current controllers can be applied to PHAPF. A direct current controller uses only source currents to compensate harmonics and/or reactive power. An indirect current controller uses both load and filter currents to maintain harmonics and/or reactive power compensation. The indirect current control method is preferred in many of PHAPF studies [22-28] and direct current control method is applied and investigated in fewer studies [12, 19, 2932]. In indirect current control, the grid voltage and the impedance of the passive filter must be taken into account for fundamental and harmonic frequencies in order to generate a proper voltage reference for the compensation. This approach can cause complexity in control method. Because of that, instead of using the grid voltage and the impedance of passive filter, a linear proportional controller is preferred for the calculation of reference voltage. However, the linear proportional controller presents moderate performance in the compensation of harmonics. In direct current control, PHAPF can present a faster dynamic compensation performance and the current reference is generated by comparing the reference current extracted from the load current and the filter current, so grid voltage has no direct effect on the control loop. However, the second order impedance characteristic of series connected 
passive filters causes oscillations in the step response changes of low frequency components so, complex controller methods must be preferred for the control of fundamental frequency components which are used for the dc link control and reactive power compensation.

Furthermore, the reactive power demand of the load is considered constant and reactive power compensation requirements are supplied by the constant reactive power capacity of the passive filter in a major number of PHAPF studies [12, 19, 22-32]. However, the reactive power demands of loads show variable reactive power characteristics in most industrial applications and PHAPF can be one of the effective solutions for harmonics compensation and variable reactive demand of industrial loads. The dynamic reactive power compensation is investigated in [29, 33]. In [21, 29, 33], the adaptive dc link voltage control is employed and the dc link voltage is changed according to the dynamic reactive power compensation requirements. In [29], adaptive dc link voltage control is achieved according to both harmonic currents and reactive power requirements of the load by using the selective harmonic extraction method. In these studies, direct current control approach is preferred for harmonics and dynamic reactive power compensation so both active and reactive parts of PHAPF currents must be controlled with different controllers for the dc link control in order to maintain the dc link voltage in step response changes of load. Also, the dynamic reactive power compensation performance of $10 \mathrm{kVA}$ PHAPF is investigated with only a few hundred of Var reactive power which is relatively low for investigating the performance of 10kVA PHAPF.

On account of the limitations in the above mentioned literature, the purpose of this paper is the following:

1. A new control approach is proposed in order to ensure ac current shaping, reactive power dynamical compensation, and dc voltage regulation.

2. This control method is applied in medium voltage levels.

3. Theoretical analyses and simulation results are obtained from an actual industrial network model in PSCAD.

4. The simulation results are presented for a proposed system in order to demonstrate that the harmonic compensation performance meets the requirements of the IEEE-519 standard.

5. To apply dynamic load changes and observe the system response.

\section{PARALLEL HYBRID ACTIVE POWER FILTER}

To explain both harmonics and reactive power compensation characteristics of the PHAPF, the single phase equivalent circuit is shown in Figure $1(\mathrm{a}) . Z_{\mathrm{s}}$ presents the source impedance and $Z_{f}$ presents the passive filter impedance. The nonlinear load is indicated as an ideal current source $\left(\mathrm{I}_{\mathrm{L}}\right)$, and the APF is shown as a voltage source.

If the terminal voltage does not have a fundamental component, the voltage across the PWM inverter can be presented as $\mathrm{K} \cdot \mathrm{I}_{\mathrm{sh}}$ at harmonic frequencies where ' $h$ ' shows the harmonic components and $\mathrm{K}$ shows the feedback gain.
Therefore, the source voltage can become pure $50 \mathrm{~Hz}$ and presenting the current directions as in Figure 1(b), the following equations can be obtained by applying Kirchhoff's voltage law:

$$
\mathrm{V}_{\mathrm{sh}}-\mathrm{I}_{\mathrm{sh}} \mathrm{Z}_{\mathrm{sh}}-\mathrm{I}_{\mathrm{fh}} \mathrm{Z}_{\mathrm{fh}}-\mathrm{V}_{\mathrm{af}}=0
$$

where,

$$
\begin{gathered}
\mathrm{V}_{\mathrm{sh}}=0, \mathrm{~V}_{\mathrm{af}}=\mathrm{K} \cdot \mathrm{I}_{\mathrm{sh}} \\
\mathrm{I}_{\mathrm{sh}}=\mathrm{I}_{\mathrm{Lh}}+\mathrm{I}_{\mathrm{fh}} \\
\mathrm{I}_{\mathrm{sh}}=\frac{\mathrm{Z}_{\mathrm{fh}}}{\mathrm{Z}_{\mathrm{fh}}+\mathrm{Z}_{\mathrm{sh}}+\mathrm{K}} \cdot \mathrm{I}_{\mathrm{Lh}}
\end{gathered}
$$

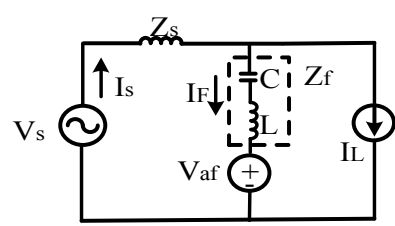

(a)

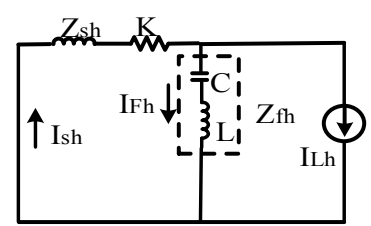

(b)
Fig. 1. (a) Single phase equivalent circuit, (b) Harmonic equivalent circuit

Equation (4) shows that the active part of the filter is connected to the system and feedback gain $\mathrm{K}$ acts as a damping resistor. $\mathrm{K}$ protects the resonance between the supply and the passive filter. Theoretically, as $\mathrm{K}$ goes to infinity, the harmonic content of the source current goes towards zero. However due to stability problems in the control loop, the gain $\mathrm{K}$ should be limited to certain values [34]. Hence the design procedure of PHAPF can be divided into two groups as the design of the passive filter and the design of the active filter part. The design of the passive filter is mainly identifying the $\mathrm{L}_{\mathrm{f}}, \mathrm{C}_{\mathrm{f}}$ parameters considering the harmonic content of the load. It is clear that, the tuning frequency of the passive filter is chosen to be the most dominant harmonic component of the nonlinear load.

Today's industrial loads generally use three phase diode rectifiers as $\mathrm{AC} / \mathrm{DC}$ converters, instead of PWM converters, due to their low cost and efficiency. As a result, in the case of a diode rectifier, the passive filter should be adjusted to eliminate the 5th or 7th harmonic current content. The 5th harmonic current content of a diode rectifier is higher than its 7 th harmonic components, so it is more reasonable to tune passive filter around $250 \mathrm{~Hz}$. LC filter for this work is tuned at $250 \mathrm{~Hz}$.

\section{PROPOSED CONTROL METHOD}

The proposed system is represented in Figure 2. The control scheme of the M-PHAPF is based on the synchronous reference frame method which presents easy implementation and low computational cost. The proposed controller of the proposed system consists of four main parts. These parts are the harmonic compensation controller, the reactive power compensation controller, the dc link reference voltage calculation and controller and finally, the reference calculation and gate signal generation. 


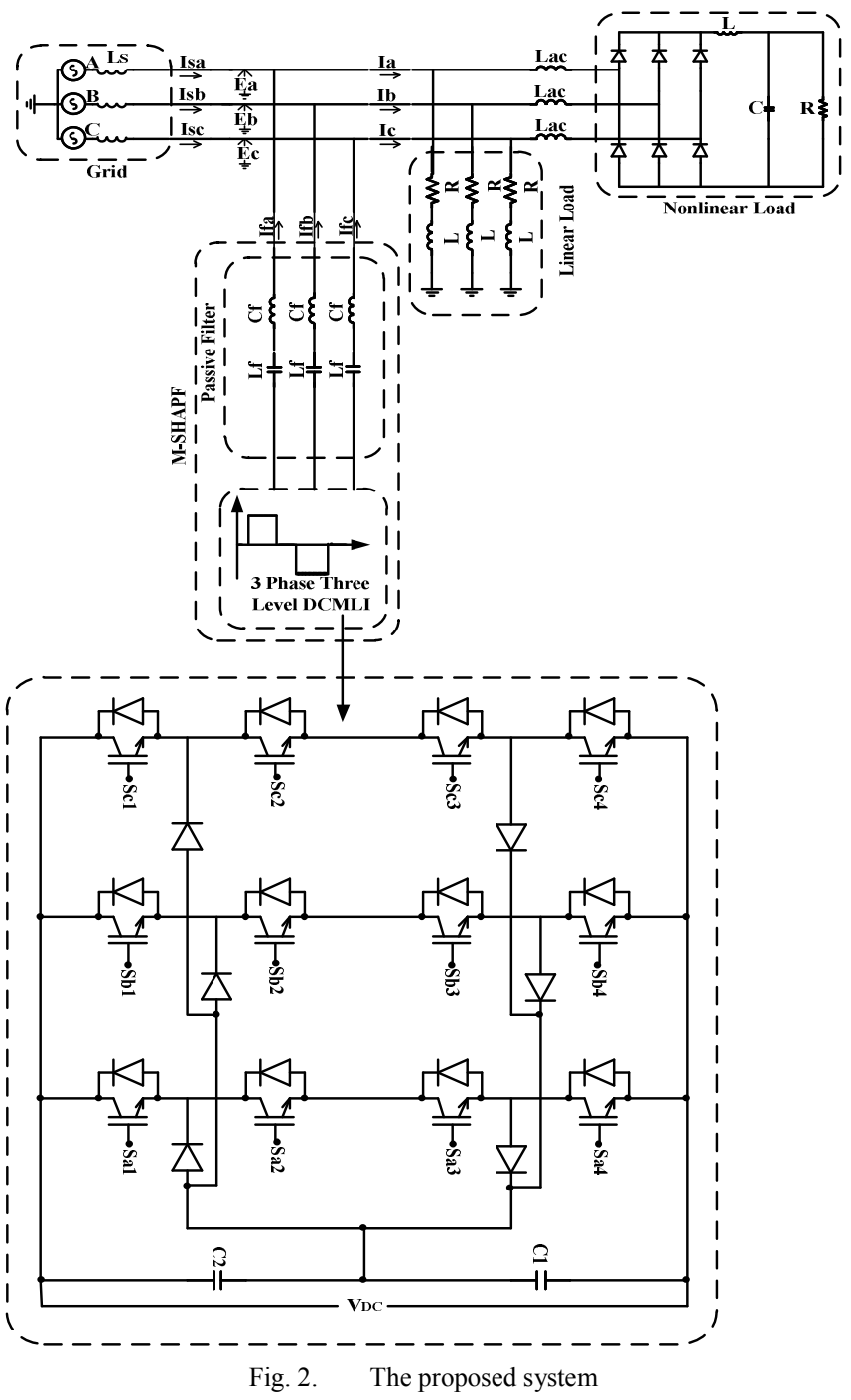

\section{A. Harmonic Current Controler}

The harmonic control of M-PHAPF is shown in Figure 3. The first step is to isolate the harmonic components from the fundamental component of the grid currents. This is achieved through the dq transformation (6), synchronized with the PCC voltage vector, and a first order low pass filter (LPF) with a cut off frequency of $10 \mathrm{~Hz}$. Then the dq inverse transformation (8) produces the harmonic currents in the abc referential frame.

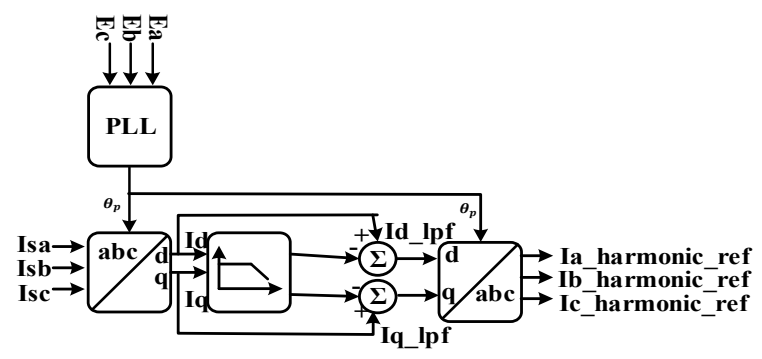

Fig. 3. Harmonic current control
The conversion matrix is

$$
\mathrm{T}_{\mathrm{dq}}^{123}=\sqrt{\frac{2}{3}}\left[\begin{array}{ccc}
\cos \theta_{\mathrm{p}} & \cos \left(\theta_{\mathrm{p}}-2 \pi / 3\right) & \cos \left(\theta_{\mathrm{p}}+2 \pi / 3\right) \\
-\sin \theta_{\mathrm{p}} & -\sin \left(\theta_{\mathrm{p}}-2 \pi / 3\right) & -\sin \left(\theta_{\mathrm{p}}+2 \pi / 3\right) \\
\frac{\sqrt{2}}{2} & \frac{\sqrt{2}}{2} & \frac{\sqrt{2}}{2}
\end{array}\right]
$$

And the inverse conversion matrix is

$$
\begin{aligned}
& \mathrm{T}_{123}^{\mathrm{dq}}=\sqrt{\frac{2}{3}}\left[\begin{array}{ccc}
\cos \theta_{\mathrm{p}} & -\sin \theta_{\mathrm{p}} & \frac{\sqrt{2}}{2} \\
\cos \left(\theta_{\mathrm{p}}-2 \pi / 3\right) & -\sin \left(\theta_{\mathrm{p}}-2 \pi / 3\right) & \frac{\sqrt{2}}{2} \\
\cos \left(\theta_{\mathrm{p}}+2 \pi / 3\right) & -\sin \left(\theta_{\mathrm{p}}+2 \pi / 3\right) & \frac{\sqrt{2}}{2}
\end{array}\right] \\
& {\left[\begin{array}{l}
\mathrm{i}_{a_{\text {__harmonic_ref }}} \\
\mathrm{i}_{\mathrm{b} \_ \text {harmonic_ref }} \\
\mathrm{i}_{\text {c_harmonic_ref }}
\end{array}\right]=\mathrm{T}_{123}^{\mathrm{dq}}\left[\begin{array}{l}
\mathrm{i}_{\mathrm{d} \_ \text {lpf }} \\
\mathrm{i}_{\mathrm{q} \_ \text {lpf }} \\
\mathrm{i}_{\text {o_lpf }}
\end{array}\right]}
\end{aligned}
$$

\section{B. Reactive Power Compensation Control}

When the loading reactive power $\mathrm{Q}_{\mathrm{Lxf}}$ is greater than $\mathrm{Q}_{\mathrm{cxfPF}}$, in order to generate a larger $\mathrm{I}_{\mathrm{cxf}}$, the inverter should output $\mathrm{a}$ negative inverter fundamental active voltage $\left(\mathrm{V}_{\text {invxf }}<0\right)$ [12]. The reactive power equivalent circuit is shown in Figure 4 . The related equations are as follows:

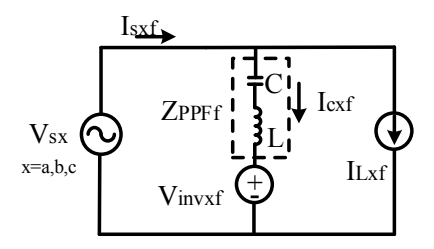

Fig. 4. Reactive power equivalent sircuit

$$
\begin{gathered}
\mathrm{V}_{\text {invxf }}=\mathrm{V}_{\mathrm{sx}}-\mathrm{Z}_{\mathrm{PFFf}} \mathrm{I}_{\mathrm{cxf}} \\
\mathrm{I}_{\mathrm{cxf}}=\frac{\mathrm{V}_{\text {invxf }}-\mathrm{V}_{\mathrm{sx}}}{\mathrm{Z}_{\mathrm{PPFf}}} \\
\mathrm{X}_{\mathrm{PPFf}}=-\left|\mathrm{X}_{\mathrm{cf}}-\mathrm{X}_{\mathrm{Lf}}\right|
\end{gathered}
$$

The reactive power provided by the passive part

$$
Q_{\mathrm{cxfPF}}=-\frac{\mathrm{V}_{\mathrm{sx}}{ }^{2}}{\left|\mathrm{X}_{\mathrm{cf}}-\mathrm{X}_{\mathrm{Lf}}\right|}<0
$$




\section{DC Link Voltage Reference Calculation and Controller}

The reference dc link voltage is determined with (15) by using (13) and (14). Moreover, a proportional-integral controller is used to control the PHAPF de bus voltage shown in Figure 5.

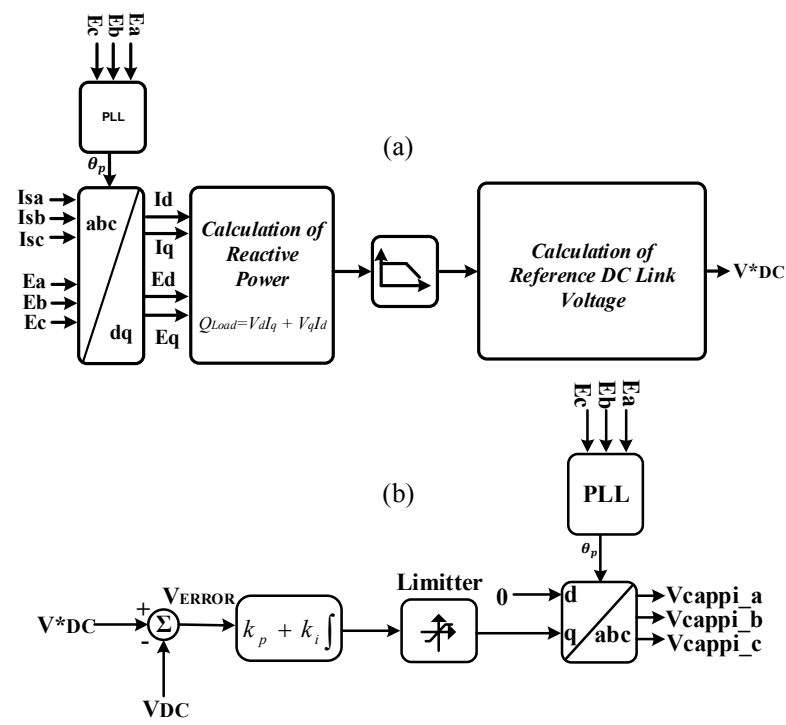

Fig. 5. DC link voltage controller (a) calculation of adaptive DC link voltage (b) DC link PI controller

For harmonic compensation only, the required DC link voltage value is:

$$
\sum_{\mathrm{h}^{1} 1}^{\mathrm{n}} \mathrm{Z}_{\mathrm{F}, \mathrm{h}} \cdot \mathrm{I}_{\text {filter,h }}<\mathrm{V}_{\mathrm{DC}(\text { harmonic) }}
$$

Where $\mathrm{h}$ represents the order of the harmonic, $\mathrm{I}_{\text {filter, }}$ is the filter current and $\mathrm{Z}_{\mathrm{F}, \mathrm{h}}$ is the impedance of the LC filter at the corresponding harmonic frequency.

For reactive power compensation only, the required DC link voltage value is [12]:

$$
\begin{gathered}
\mathrm{V}_{\mathrm{DC} \text { (reactive) }}=3 \frac{\sqrt{2}}{2} \mathrm{~V}_{\mathrm{PCC}}\left|1-\frac{\mathrm{Q}_{\text {Load }}}{\mathrm{Q}_{\text {Passivefilter }}}\right| \\
\mathrm{V}_{\mathrm{DC}}^{*}=\mathrm{V}_{\mathrm{DC} \text { (harmonic) }}+\mathrm{V}_{\mathrm{DC} \text { (reactive) }}
\end{gathered}
$$

$\mathrm{V}_{\mathrm{DC}}^{*}$ is the dc link reference value for both harmonic and reactive power compensation. By using the error signal generated by the conventional PI controller, the dq inverse transformation (16) produces the reference DC link control signals in the abc referential frame. A limiter is also applied to avoid the overflow problem of the controller. DC link is controlled by the reactive component of the error signal. Thus, only the q component is used for dq inverse transformation.

$$
\left[\begin{array}{c}
\mathrm{V}_{\text {cappi_a }} \\
\mathrm{V}_{\text {cappi_b }} \\
\mathrm{V}_{\text {cappi_c }}
\end{array}\right]=T_{123}^{\mathrm{dq}}\left[\begin{array}{c}
0 \\
\mathrm{~V}_{\text {errror }} \\
0
\end{array}\right]
$$

\section{Multilevel Inverter Control, Final Reference Compensation Current and PWM Control Block}

The diode clamped inverter is the most popular and the most commonly used multilevel topology in industrial applications. Three level diode clamped inverter is used for the proposed system. This topology provides three voltage levels: $\mathrm{V}_{\mathrm{DC}} / 2,0,-\mathrm{V}_{\mathrm{DC}} / 2$ when the neutral point is replaced in the middle point of $\mathrm{C} 1$ and $\mathrm{C} 2$. If the neutral point is removed, the three voltage levels have become $\mathrm{V}_{\mathrm{DC}},-\mathrm{V}_{\mathrm{DC}}, 0$. Each bridge in this topology generates three different voltage levels:

-To generate phase-neutral voltage which is equal to $\mathrm{V}_{\mathrm{DC}} / 2$ turn on only $\mathrm{S}_{\mathrm{n} 1}$ and $\mathrm{S}_{\mathrm{n} 2}$.

-To generate phase-neutral voltage which is equal to 0 , turn on only $\mathrm{S}_{\mathrm{n} 2}$ and $\mathrm{S}_{\mathrm{n} 3}$.

-To generate phase-neutral voltage which is equal to $-\mathrm{V}_{\mathrm{DC}} / 2$, turn on only $\mathrm{S}_{\mathrm{n} 3}$ and $\mathrm{S}_{\mathrm{n} 4}$.

The final reference current consists of three phase harmonic reference current signals, three phase reactive reference current signals and dc link control signals. The reference signal (In_harmonic_ref + In_reactive_ref + Vcappi_n, $n=a, b, c$ ) is generated using these signals together. Then, the reference signals are compared with carrier signal to generate switching signals shown in Figure 6.

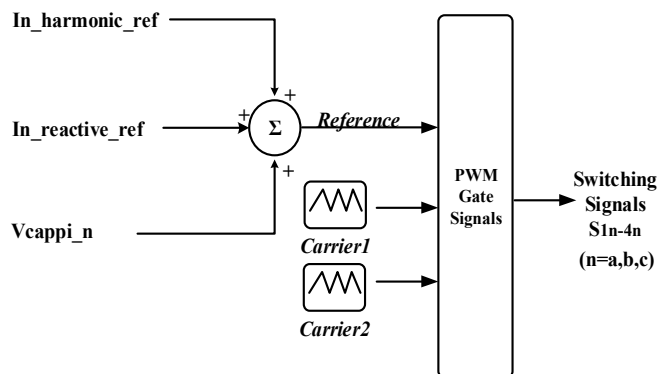

Fig. 6. Final reference compensation and PWM control method

\section{SimULATION RESULTS}

In this paper, the simulation model of the system is formed by using the EMTDC/PSCAD 4.2.0 software. The Parallel Hybrid Power Filter system and the Multilevel Hybrid Active Power Filter are modelled, simulated and analysed in the PSCAD 4.2.0 environment. All control methods are developed in FORTRAN language. The simulation parameters of the system are given in Table I respectively.

According to most articles in the literature, PHAPF has a reactive power compensation capability that is limited with the capacity of the used passive filter. Simulation results, clearly show that the reactive power compensation capability is added 
to the M-PHAPF by using the APF part and also the dynamic dc link. In this case, the capacity of the passive filter is nearly $205 \mathrm{kVAR}$. When the first load is connected, the load capacity is nearly $220 \mathrm{kVAR}$. The simulation results show that the APF part of Multilevel-PHAPF compensates nearly $15 \mathrm{kVAR}$ reactive power with the adjusted DC link voltage which is nearly $1 \mathrm{kV}$. When the first and the second loads are connected, the load capacity is nearly $380 \mathrm{kVAR}$. The simulation results show that the APF part of Multilevel-PHAPF compensates nearly $20 \mathrm{kVAR}$ reactive power with the adjusted DC link voltage which is nearly $1.5 \mathrm{kV}$.

The DC link voltage is adjusted itself by changing the load capacity. The filtering performance of the system and the DC link voltage are shown in Figures 7 and 8. The reactive power compensation performance is illustrated in Figure 9. The total harmonic distortion (THD) is reduced from $28.4 \%$ to $3.88 \%$ when the first is connected (Figure 10). The total harmonic distortion (THD) is reduced from $20 \%$ to $1.63 \%$ when the first and the second loads are connected (Figure 11).

TABLE I. SIMULATION PARAMETERS

\begin{tabular}{|c|c|c|c|}
\hline $\mathbf{V}_{\text {Line(V) }}$ & 6300 & $\mathbf{L}_{\mathbf{F}}(\mathbf{H})$ & 0.025 \\
\hline $\mathbf{f}_{\text {Line }(\mathbf{H z})}$ & 50 & $\mathbf{f}_{\text {switching }}(\mathbf{k H z})$ & 10 \\
\hline $\mathbf{L s}(\mathbf{H})$ & 0.001 & $\mathbf{T}_{\text {st }}(\boldsymbol{\mu s})$ & 40 \\
\hline $\mathbf{L l}(\mathbf{m H})$ & 0.6 & $\mathbf{f}_{\text {tuned }}(\mathbf{H z})$ & 250 \\
\hline $\mathbf{C}_{\mathbf{F}}(\boldsymbol{\mu} \mathbf{F})$ & 16 & $\mathbf{C}_{\mathbf{D C} 1}, \mathbf{C}_{\mathbf{D C} 2}(\boldsymbol{\mu} \mathbf{F})$ & 1000 \\
\hline
\end{tabular}

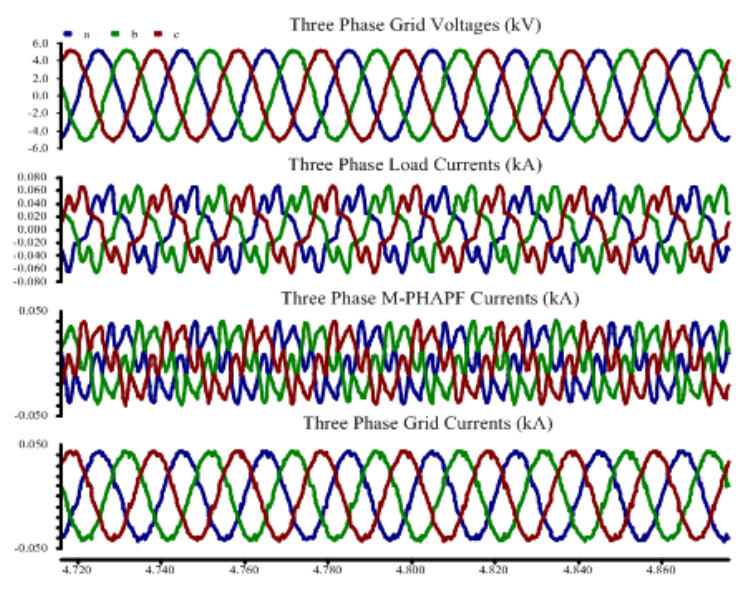

Fig. 7. Multilevel PHAPF operates

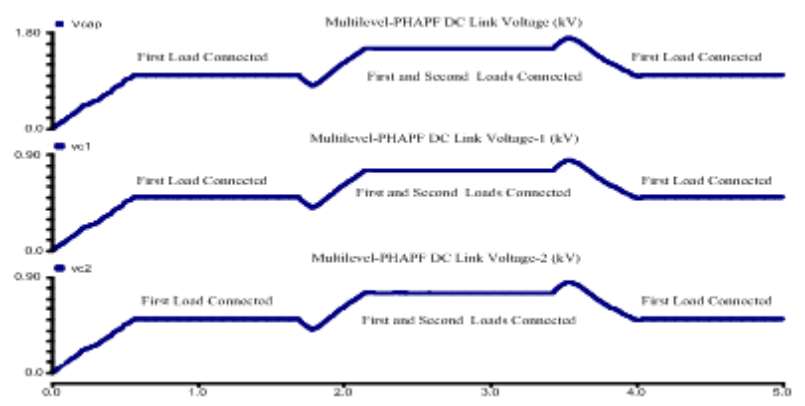

Fig. 8. DC link voltage of HAPF

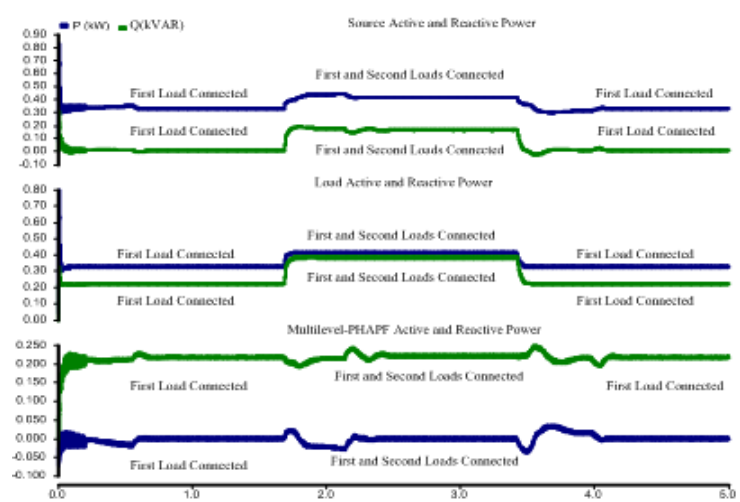

Fig. 9. Source active and reactive power, load active and reactive power

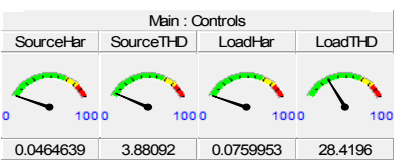

Fig. 10. Simulation results (first load connected)

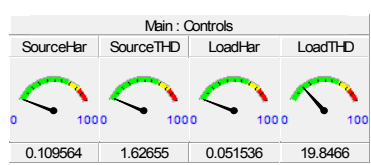

Fig. 11. Simulation results (first and second load connected)

\section{CONCLUSIONS}

A new control approach is used, in order to ensure the ac current shaping, compensate the reactive power dynamically and regulate the dc voltage for the three phase shunt hybrid active power filter. This control scheme of the M-PHAPF is based on the synchronous reference frame and is simpler and easier to implement. The harmonic compensation is obtained by regulating the currents of the power systems. The reference reactive power compensation currents of the M-PHAPF are generated from the power systems. The dc link voltage control signals are based on the reactive power balance of system. The dynamic reactive power compensation is achieved successfully with a perceptible amount. Besides, the harmonic compensation performance is satisfactory. The simulation results of the three phase three wire PHAPF under the dynamic reactive power compensation are illustrated to verify all discussion and analysis and also show the effectiveness of the proposed controller. Hence, the proposed M-PHAPF system can be an effective and economic solution for both harmonic and reactive power problems caused by the large capacity of linear and nonlinear loads.

\section{ACKNOWLEDGMENT}

The authors gratefully acknowledge Scientific Research Projects Unit of Çukurova University, Adana, Turkey (Project No: MMF2012YL22) for full financial support. 


\section{REFERENCES}

[1] X. Zha, J. Sun, J. Gong, B. Chen, "Analysis and design of repetitive controller based on regeneration spectrum and sensitivity function in active power filter system", IET Power Electron., Vol. 7, No. 8, pp, 2133-2140, 2014

[2] M. C. Shah, S. K. Chauhan, P. N. Tekwani,. R. R. Tiwari, “Analysis, design and digital implementation of a shunt active power filter with different schemes of reference current generation", IET Power Electron., Vol. 7, No. 3, pp. 627-639, 2014

[3] B. Qin, H. Zhu, S. Gao, Z. Shu, F. Gao, "Five-level diode-clamped active power filter using voltage space vector-based indirect current and predictive harmonic control", IET Power Electron., Vol. 7, No. 3, pp. 713-723, 2014

[4] S. K. Khadem, M. Basu, M. F. Conlon, "Harmonic power compensation capacity of shunt active power filter and its relationship with design parameters", IET Power Electron., Vol. 7, No. 2, pp. 418-430, 2014

[5] J. Solsona, C. A. Busada, S. Gomez Jorge, "Reduced order generalised integrator-based current controller applied to shunt active power filters", IET Power Electron., Vol. 7, No. 5, pp. 1083-1091, 2014

[6] Q. Chen, R. Yuan, X. Deng, P. Guo, Z. Xiao, "Shunt active power filter with enhanced dynamic performance using novel control strategy", IET Power Electron., Vol. 7, No. 12, pp. 3169-3181, 2014

[7] J. Turunen, M. Salo, H. Tuusa, "Comparison of three series hybrid active power filter topologies", 11th International Conference on Harmonics and Quality of Power, pp. 324-329, 2004

[8] A. Chowdhury, C. Rajagopalan, M. A. Mulla, "Hardware implementation of series hybrid active power filter using a novel control strategy based on generalised instantaneous power theory", IET Power Electron., Vol. 6, No. 3, pp. 592-600, 2013

[9] A. Chowdhury, C. Rajagopalan, M. A. Mulla, "Compensation of threephase diode rectifier with capacitive filter working under unbalanced supply conditions using series hybrid active power filter", IET Power Electron., Vol. 7, No. 6, pp. 1566-1577, 2014

[10] D. Shaojun, L. Jianben, T. Kun, C. Qiaofu, "Modelling and industrial application of series hybrid active power filter", IET Power Electron., Vol. 6, No. 8, pp. 1707-1714, 2013

[11] M. Chau, A. Luo, F. Ma, Z. Shuai, T. Nguyen, W. Wang, "Online control method with time-delay compensation for hybrid active power filter with injection circuit", IET Power Electron., Vol. 5, No. 8, pp. 1472-1482, 2012

[12] C. -S. Lam, W. -H. Choi, M. -C. Wong, Y. -D. Han, "Adaptive de-link voltage-controlled hybrid active power filters for reactive power compensation", IEEE Trans. Power Electron., Vol. 27, No. 4, pp. 1758 1772,2012

[13] S. Rahmani, A. Hamadi, K. Al-Haddad, L. A. Dessaint, "A combination of shunt hybrid power filter and thyristor-controlled reactor for power quality", IEEE Trans. Ind. Electron., Vol. 61, No. 5, pp. 2152-2164, 2014

[14] J. Wu, A. Luo, S. Peng, F. Ma, Z. Zeng, M. T. Chau, "System control of hybrid active power filter for reactive power compensation and harmonic suppression", 6th IEEE Conference on Industrial Electronics and Applications, pp. 862-866, 2011

[15] M. Salehifar, A. Shoulaie, "Hybrid active filter for harmonic suppression and reactive power compensation", IEEE International Conference for Technical Postgraduates, pp. 1-4, 2011

[16] W. Zhao, A. Luo, J. Peng, X. Deng, K. Peng, “A new hybrid active power filter for harmonic suppression and reactive power compensation", IEEE China International Conference on Electricity Distribution", pp. 1-7, 2008
[17] L. Herman, I. Papic, B. Blazic, "A proportional-resonant current controller for selective harmonic compensation in a hybrid active power filter”, IEEE Trans. Power Deliv., Vol. 29, No. 5, pp. 2055-2065, 2014

[18] W. Lu, C. Li, C. Xu, "Sliding mode control of a shunt hybrid active power filter based on the inverse system method", Int. J. Electr. Power Energy Syst., Vol. 57, pp. 39-48, 2014

[19] C. -S. Lam, M. -C. Wong, W. -H. Choi, X. -X. Cui, H. -M. Mei, J. -Z. Liu, "Design and performance of an adaptive low-dc-voltage-controlled lc-hybrid active power filter with a neutral inductor in three-phase fourwire power systems", IEEE Trans. Ind. Electron., Vol. 61, No. 6, pp. 2635-2647, 2014

[20] Y. Ma, J. Zhao, X. Zhou, "The research of active disturbance rejection control on shunt hybrid active power filter", Procedia Eng., Vol. 29, pp. 456-460, 2012

[21] W. -H. Choi, C. -S. Lam, M. -C. Wong, Y. -D. Han, "Analysis of dc-link voltage controls in three-phase four-wire hybrid active power filters", IEEE Trans. Power Electron., Vol. 28, No. 5, pp. 2180-2191, 2013

[22] H. Akagi, “Active harmonic filters", Proceedings of the IEEE, pp. 2128 2141, 2005

[23] H. Akagi, K. Isozaki, "A hybrid active filter for a three-phase 12-pulse diode rectifier used as the front end of a medium-voltage motor drive", IEEE Trans. Power Electron., Vol. 27, No. 1, pp. 69-77, 2012

[24] A. Bhattacharya, C. Chakraborty, S. Bhattacharya, "Parallel-connected shunt hybrid active power filters operating at different switching frequencies for improved performance", IEEE Trans. Ind. Electron., Vol. 59, No. 11, pp. 4007-4019, 2012

[25] H. Fujita, T. Yamasaki, H. Akagi, "A hybrid active filter for damping of harmonic resonance in industrial power systems", IEEE Trans. Power Electron., Vol. 15, No. 2, pp. 215-222, 2000

[26] R. Inzunza, H. Akagi, "A 6.6-kV transformerless shunt hybrid active filter for installation on a power distribution system", IEEE 35th Annual Power Electronics Specialists Conference, pp. 4630-4636, 2004

[27] W. T. W. Tangtheerajaroonwong, T. Hatada, K. W. K. Wada, H. Akagi, "Design and performance of a transformerless shunt hybrid filter integrated into a three-phase diode rectifier", IEEE Trans. Power Electron., Vol. 22, No. 5, pp. 1882-1889, 2007

[28] J. I. Candela, P. Rodriguez, A. Luna, R. Teodorescu, F. Blaabjerg, "Proposal of a resonant controller for a three phase four wire gridconnected shunt hybrid filter", IEEE Energy Convers. Congr. Expo., 2009

[29] W. -H. Choi, Y. -D. Han, C. -S. Lam, X. -X. Cui, M. -C. Wong, "Minimum inverter capacity design for LC-hybrid active power filters in three-phase four-wire distribution systems", IET Power Electron., Vol. 5, No. 7, pp. 956-968, 2012

[30] Y. -D. Han, M. -C. Wong, C. -S. Lam, "Hysteresis current control of hybrid active power filters", IET Power Electron., Vol. 5, No. 7, pp. $1175-1187,2012$

[31] A. Luo, Z. Shuai, M. Li, M.T. Chau, L. Zhou, T. N. Nguyen, "Generalised design method for improving control quality of hybrid active power filter with injection circuit", IET Power Electron., Vol. 7, No. 5, pp. 1204-1215, 2014

[32] A. Luo, Z. Shuai, W. Zhu, Z. J. Shen, C. Tu, "Design and application of a hybrid active power filter with injection circuit", IET Power Electron., Vol. 3, No. 1, pp. 54-64, 2010

[33] C. -S. Lam, M. -C. Wong, Y. -D. Han, "Minimum dc-link voltage design of three-phase four-wire active power filters, IEEE 13th Workshop on Control and Modeling for Power Electronics (COMPEL), pp. 1-5, 2012

[34] S. Srianthumrong, H. Akagi, "A medium voltage transformerless ac/dc power conversion system consisting of a diode rectifier and a shunt hybrid filter", IEEE Transactions on Industry Applications, Vol. 39, No. 3, pp. 874-882, 2003 